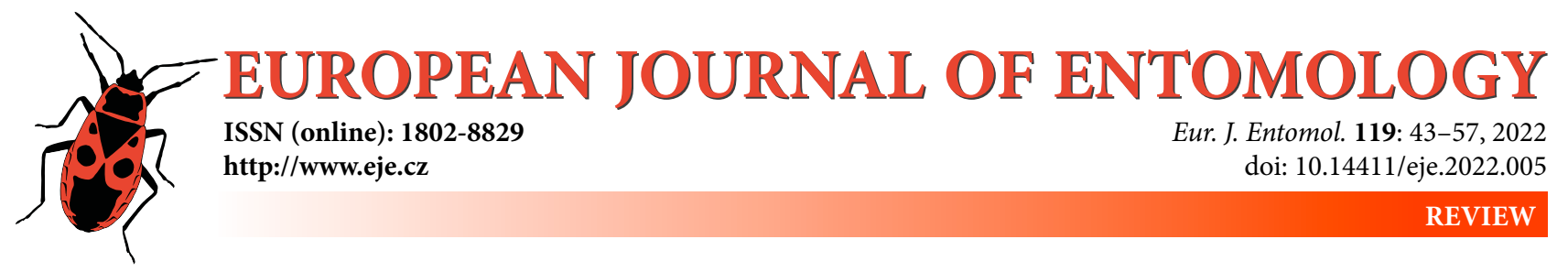

\title{
Cold and freezing injury in insects: An overview of molecular mechanisms*
}

\author{
JAN ROZSYPAL D \\ Biology Centre of the Czech Academy of Sciences, Institute of Entomology, České Budějovice, Czech Republic; \\ e-mail: rozsypal@entu.cas.cz
}

Key words. Cold injury, freezing injury, macromolecular damage

\begin{abstract}
The present review discusses the molecular mechanisms of injury caused by low temperatures and/or freezing. The review is intended mainly for insect environmental physiologists who focus on the effects of low temperatures. The review successively discusses (1) the effects of low temperatures on the structure and function of macromolecules; (2) the effects of freezing on cells and macromolecules and (3) the mechanisms of damage during thawing and post-thaw. The review shows that injury primarily occurs at the molecular level in terms of damage to proteins, nucleic acids and biological membranes. The damage to macromolecular structures occurs as a result of the interaction between the effects of temperature, ice formation and resulting secondary effects such as osmotic stress, increased concentration of solutes, cellular freeze dehydration, disruption of ionic balance and oxidative stress. The present review attempts to identify gaps in our knowledge on the mechanisms of cold injury in organisms and proposes possible future directions that could contribute to filling the gaps.
\end{abstract}

\section{INTRODUCTION}

Temperature affects every aspect of the life of insects and other organisms, from the rate of biochemical reactions, to activity, growth, development and reproduction. A definition of low temperature depends on the species considered but also depends on the actual physiological state of the organism. Low temperature can be understood as any temperature below the threshold for activity, growth, or development, for a given species. More strictly, low temperature can be defined as the temperature that causes some sort of injury, which may result in death or in various sub-lethal effects (Lee, 1991). The scope of the present review (Fig. 1) are the effects of temperatures on organisms below the critical thermal minimum $\left(\mathrm{CT}_{\min }\right)$, which can be considered to be the threshold below which cold injury can start to occur (MacMillan \& Sinclair, 2011). However, the present review will focus mostly on the damaging effects of subzero temperatures and of freezing ("cryothermia"), mainly at the molecular level. Other effects of relatively low temperatures that occur at or above $\mathrm{CT}_{\text {min }}$ will be discussed only peripherally (see section 2). The effects of "low" temperatures above $\mathrm{CT}_{\text {min }}$ mostly result from "impaired processes", causing no physical damage to the organism and they may include for example decreased metabolism, growth, reproduction, development rate, or chill coma.
Cold injury can be divided into two categories: (1) chill injury and (2) freeze injury (Storey \& Storey, 1988). Chill injury is caused by temperatures below optimum but above the temperature of crystallization of body fluids (supercooling point, SCP). Chill injury can be further divided into acute (cold shock, also referred to as direct chilling injury) and chronic/cumulative (indirect chilling injury). Acute cold injury occurs in response to a sudden and fast temperature change for a short period of time, while chronic cold injury results from longer exposures to low temperatures. Freeze injury occurs as a result of ice formation (extracellular or intracellular) within the organism. The extent of cold injury is often assessed in terms of mortality after exposure to cold. Cold injury however, does not always result in immediate death, but sometimes cold injury can be tolerated or repaired (e.g. Košt'ál et al., 2007; Štětina et al., 2018). Depending on the extent of damage and ability to repair/tolerate it, cold injury may also manifest through sub-lethal effects such as delayed mortality, delayed development, shortened lifespan and reduced fitness (Košt'ál et al., 2019).

Most studies on insect cold tolerance have focused (although rather indirectly, by determining correlates that increase cold tolerance) on the mechanisms that protect insects from the effects of low temperatures and/or freezing.

\footnotetext{
* This paper was contributed to a virtual special issue in memory of Ivo Hodek, a long-time editor of the European Journal of Entomology, who died on June 11, 2021, shortly after his ninetieth birthday.
} 


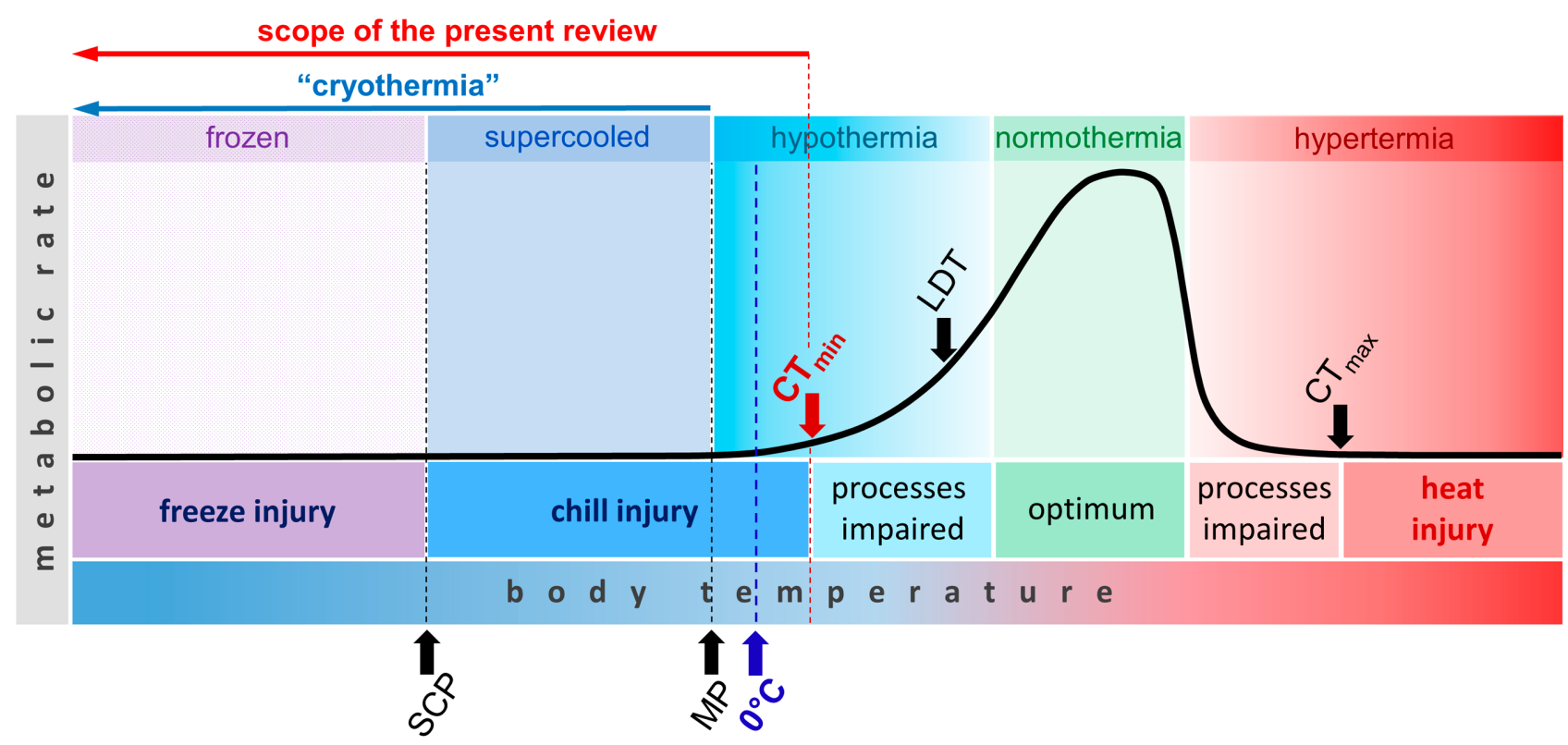

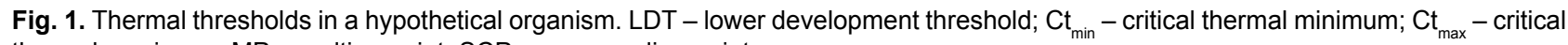
thermal maximum; MP - melting point; SCP - supercooling point.

Similarly, also reviews in this field mostly concentrate on mechanisms of "cryoprotection", while the mechanisms of cold/freezing injury are addressed rather marginally/superficially (e.g. Zachariassen, 1985; Sømme, 1999; Ramløv, 2000; Clark \& Worland, 2008; Teets \& Denlinger, 2013). Some reviews have addressed the mechanisms of cold/ freezing injury in considerable detail, however from an eco-physiological perspective, concentrating on physiological and ecological consequences rather than on the molecular/physical causes of the damage (e.g. recent review by Toxopeus \& Sinclair, 2018). The research mostly focuses on mechanisms of cryoprotection also in other fields, such as cold tolerance in plants (Mazur, 1969; Levitt, 1980; Smallwood \& Bowles, 2002) or cell/tissue cryopreservation (Meryman, 1974; Gao \& Critser, 2000; Peña et al., 2011), although mechanisms of cold injury are explored in more detail than in insects. The mechanisms of cold injury thus have received much less attention than mechanisms of protection against it.

The research on cold injury in insects and also other organisms is often only indirect, limited to a search for the conditions such as temperature or duration of exposure at temperatures under which mortality (an ultimate result of cold injury) starts to occur (e.g. Boychuk et al., 2015; Stephens et al., 2015; Rozsypal et al., 2018a). A more direct approach to studying cold injury is represented by a number of studies that assessed tissue/cell viability after lethal or non-lethal cold exposure (e.g. Lee et al., 1993; Yi \& Lee, 2003; Marshall \& Sinclair, 2011) or focus on macroscopic and/or microscopic manifestations of cold injury by comparing the structure/ultrastructure of tissues and cells prior to and after exposure to cold (e.g. Kayukawa \& Ishikawa, 2009; Des Marteaux et al., 2018; Rozsypal et al., 2018b). Other studies have investigated the effects of low temperatures and/or freezing on metabolic function (e.g. Storey \& Storey, 1985; Sinclair et al., 2004; Michaud et al., 2008), ion regulatory mechanisms (e.g. Boardman et al., 2011; Štětina et al., 2018), or focus on repair mechanisms (e.g. Colinet et al., 2010; Štětina et al., 2018). In summary, the research on the mechanisms of cold injury in insects and other organisms, is mostly limited to higher levels of organization, specifically, the cold/freezing induced changes in tissues, cells, subcellular structures, and metabolism. Because of the complexity and also inconsistency (different cells/tissues appear to be differently prone to damage; Watson \& Morris, 1987; Marshall \& Sinclair, 2011) of damage at higher levels of organization, the mechanisms responsible for cold injury are often perceived as largely unknown.

The present review shows that contrary to the common perception, the mechanisms of cold injury in organisms are largely known, if we change our perspective and focus on the molecular level. The deeper understanding of the primary (i.e. molecular) causes of cold injury has come from the studies of molecular biophysicists. Through experimentation, analytical modelling, and computer simulations of the behaviour of macromolecules under various conditions, it has been shown that damage caused by cold/freezing occurs directly to macromolecular structures. Cold injury thus must logically cascade up from macromolecules to higher levels of organization and ultimately may affect the whole organism. However, although the basic molecular mechanisms of cold injury are known, their relationship to the damage at higher levels of organization is not clear. For instance, there are quite a few examples of vitally important enzymes surviving cold/freezing death of whole organism (see section 3.1.1.), which indicates that molecular and organismal injury may not always be related. The effect of some factors, commonly considered harmful, also is unclear. For example, freeze dehydration is fundamentally different from dehydration by drying and thus, contrary to 
the common belief, freeze dehydration may not be sufficient to destabilize macromolecules (see section 4.4.2.).

The aim of the present review is not to be exhaustive but to summarize existing concepts of the molecular mechanisms of cold injury in organisms from a physical point of view (within the capabilities of the author as a biologist) and to introduce them to insect environmental physiologists. The review is not intended to be about cold injury in insects but about molecular mechanisms of cold injury in general, although examples from insect literature are used when possible. As all organisms on Earth share the same basic macromolecular makeup (they are composed of proteins, nucleic acids and phospholipids), most molecular mechanisms of cold injury are likely to be common to all organisms, including insects. The mechanistic underpinnings of cold injury in organisms thus will be discussed with particular emphasis on the molecular level. The review will first focus on the effects of low temperatures on the structure and function of macromolecules. Then it will concentrate on the effects of freezing on cells and macromolecules. The last section of the review will focus on the mechanisms of damage during thawing and post-thaw.

\section{EFFECTS OF SUBOPTIMAL TEMPERATURES ON ORGANISMAL PHYSIOLOGY}

Perhaps the most obvious response of insects and other organisms to decreasing body temperature is a decline in activity. When temperature decreases below a certain limit, all movements cease (see schematic diagram of thermal thresholds in organisms in Fig. 1). This response of organisms to low temperatures is termed "chill coma" and the temperature at which chill coma occurs is referred to as critical thermal minimum $\left(\mathrm{CT}_{\min }\right)$. The $\mathrm{CT}_{\min }$ may range from temperatures well above $0^{\circ} \mathrm{C}$ to temperatures below the melting point of body fluids (supercooled state), depending on species and the physiological state of the organism. Chill coma in insects most likely occurs due to disruption of signal transmission through a loss of ion homeostasis in the neuromuscular system, leading to a lack of neuro-muscular coordination needed for movement (for review see MacMillan \& Sinclair, 2011; MacMillan \& Overgaard, 2017). Chill coma is reversible after rewarming, however longer exposures and/or lower temperatures may increase risk of cold injury through loss of ion homeostasis that can cause apoptosis or necrosis (Yu et al., 2001; Bayley et al., 2018).

When an organism is exposed to temperatures below optimal/"permissive" (which do not cause any injury), the main effect of temperature at the molecular level concerns the rate of chemical reactions. In living organisms, chemical reactions are mediated (catalysed) by enzymes. Some chemical reactions (more precisely some components of metabolism) are also dependent on the proper functioning of biological membranes. The function of both enzymes and biological membranes is temperature dependent. A decrease in temperature changes the conformation of enzymes, which affects the binding affinity of enzymes for substrates (Franks \& Hatley, 1991). In the case of mem- branes, temperature changes their fluidity, which have effects on membrane permeability and also on the function of membrane bound proteins (Quinn, 1988). These changes affect the rate of metabolism and of other biochemical reactions (e.g. those involved in the function of the neuromuscular system), which may result, for example, in overall decline in organismal activity. In summary, temperatures below optimal or "permissive" levels, but above critical thermal minimum basically affect processes (i.e. chemical reactions, when considering the molecular level), which may have consequences for example for organismal performance, reproduction, development, distribution, etc. but cause no physical damage (for more information on the effects of "mild" low temperatures see for example Gilbert \& Raworth, 1996; Overgaard \& Macmillan, 2017; MacMillan, 2019).

\section{INJURY CAUSED BY LOW TEMPERATURES}

If temperature is low enough (i.e. below the critical thermal minimum or much lower), it may cause damage to organisms by disrupting the conformation of macromolecules of which the organisms are composed. Damage to macromolecular structures by low temperatures (and by freezing) is the main focus of the present review. Fig. 2 shows a simplified diagram of the factors involved in cold injury in organisms and their possible interactions that can eventually result in cold injury.

\subsection{Effects of low temperatures on macromolecular structures}

\subsubsection{Proteins}

The function of proteins depends on their three-dimensional structure (conformation), as do the structures of other biomolecules, like membrane lipids and nucleic acids. Temperature is one of the factors that can strongly affect the structure, stability and thus function of macromolecules through changes to their conformation. The catalytic function of enzymes depends on their ability to (1) maintain conformation in order to bind to a substrate and (2) change conformation in order to process and release a substrate (Teilum et al., 2011; Karshikoff et al., 2015). In other words, an enzyme must be stable enough to keep its functional conformation, but also flexible enough to keep its catalytic function. Thus, the optimal function of enzymes is a trade-off between stability and flexibility. The primary structure of proteins is defined by the sequence of amino acids linked with peptide bonds (covalent interactions) and is relatively stable at the wide range of temperatures normally occurring in nature (Tattersall et al., 2012). The higher levels of structure, which define the three-dimensional conformation, are maintained by noncovalent interactions, such as hydrogen bonds, hydrophobic interactions and salt bridges (Richardson, 1981). Since noncovalent interactions are about an order of magnitude weaker than covalent interactions, the higher levels of protein structure are more sensitive to temperature and other factors. The hydrophobic effect is considered to be the main force responsible for folding and stability of pro- 


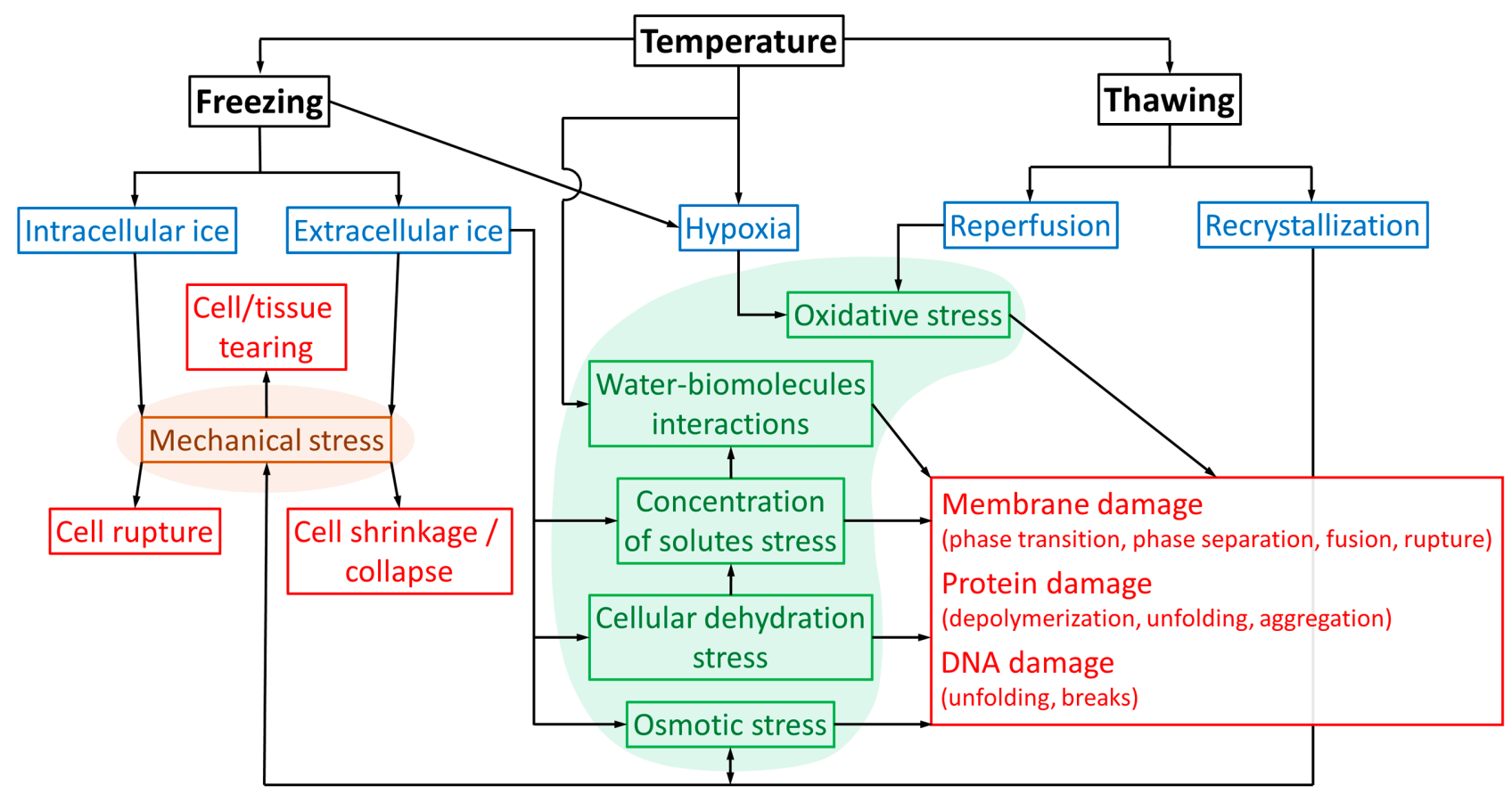

Fig. 2. Factors involved in cold injury and their interactions. A simplified diagram showing the factors involved in cold injury in organisms and their interactions. The brown area marks mechanical stress resulting from direct mechanical action of ice crystals (direct effects of ice formation). The green area marks physico-chemical stress, which results from indirect (secondary) effects of ice formation and low temperatures. Blue colour indicates other stresses and red colour injury.

teins at physiological temperatures. The hydrophobic effect causes the hydrophobic parts of polypeptide chain to fold inside a three-dimensional protein structure, while the hydrophilic parts are exposed on the surface and interact with water molecules surrounding the protein (Privalov \& Gill, 1988). The hydrophobic effect is based on properties of water, specifically the ability of water molecules to hydrogen-bond with each other and also with other hydrophilic substances. Hydrophobic and non-polar substances are displaced from the hydrogen-bonded structure of water and tend to aggregate, thus facilitating protein folding.

The way temperature influences the conformation of proteins and of other macromolecular structures is by its effect on the strength of noncovalent interactions. The main mechanism responsible for cold denaturation of proteins is thought to be a relatively weaker hydrophobic effect at low temperatures (Privalov, 1990; Dias et al., 2010). The hydrophobic parts of proteins and nonpolar solvents do not hydrogen-bond with water, and so water molecules must accommodate ("bypass") such structures by forming clathrates. Clathrate is a cage-like structure formed by water molecules around a hydrophobic object (Teeter, 1991; Dill et al., 2005). The formation of clathrates (ordered structures) significantly reduces the entropy of the system. At temperatures optimal for normal function of proteins, the water molecules have higher energy, which makes formation of clathrate structures less favourable and thus the hydrophobic effect is stronger at high temperatures. At low temperatures, water molecules have less energy, which favours the formation of clathrate structures and thus the hydrophobic effect is weaker at low temperatures (Franks, 1995; Chi et al., 2003; Dias et al., 2010).
Simply put, the hydrophobic effect is not strong enough at low temperatures to keep hydrophobic parts of proteins folded inside their structure. The hydrophobic parts can then be exposed on the surface and the protein unfolds (denatures). Unfolded proteins may further aggregate through interactions between their respective exposed hydrophobic parts. The likelihood of a protein refolding (renaturation) depends on temperature and time of exposure to the temperature, which affects the size of the aggregates and large aggregates are less likely to refold (Das et al., 2007; Wang et al., 2010). Thus, the formation of large aggregates could be one of the causes of injury during prolonged exposures to low temperatures ("chronic" chilling injury).

Although protein damage is often considered to be one of the main causes of cold injury, evidence against this exist as many enzymes can actually regain their functional conformation after cold denaturation at or near $0^{\circ} \mathrm{C}$ (see Privalov, 1990 for examples). On the other hand, many enzymes are multimeric and exposure to low temperature might only cause the dissociation of their subunits (disruption of quaternary structure). Dissociation of subunits (depolymerisation) upon exposure to cold is known also in structural proteins constituting cytoskeletal structures (Schwarzerová et al., 2003). The experimental study of protein cold denaturation is, however, problematic simply because water tends to freeze at $0^{\circ} \mathrm{C}$. To achieve sub-zero temperatures, higher pressures are applied to prevent water from freezing. Even under freezing temperatures (and high pressures), some proteins denature reversibly (for example RNAse A or egg white lysozyme) (Kunugi \& Tanaka, 2002). Most studies on protein temperature denaturation have been done in in-vitro systems, however there is also 


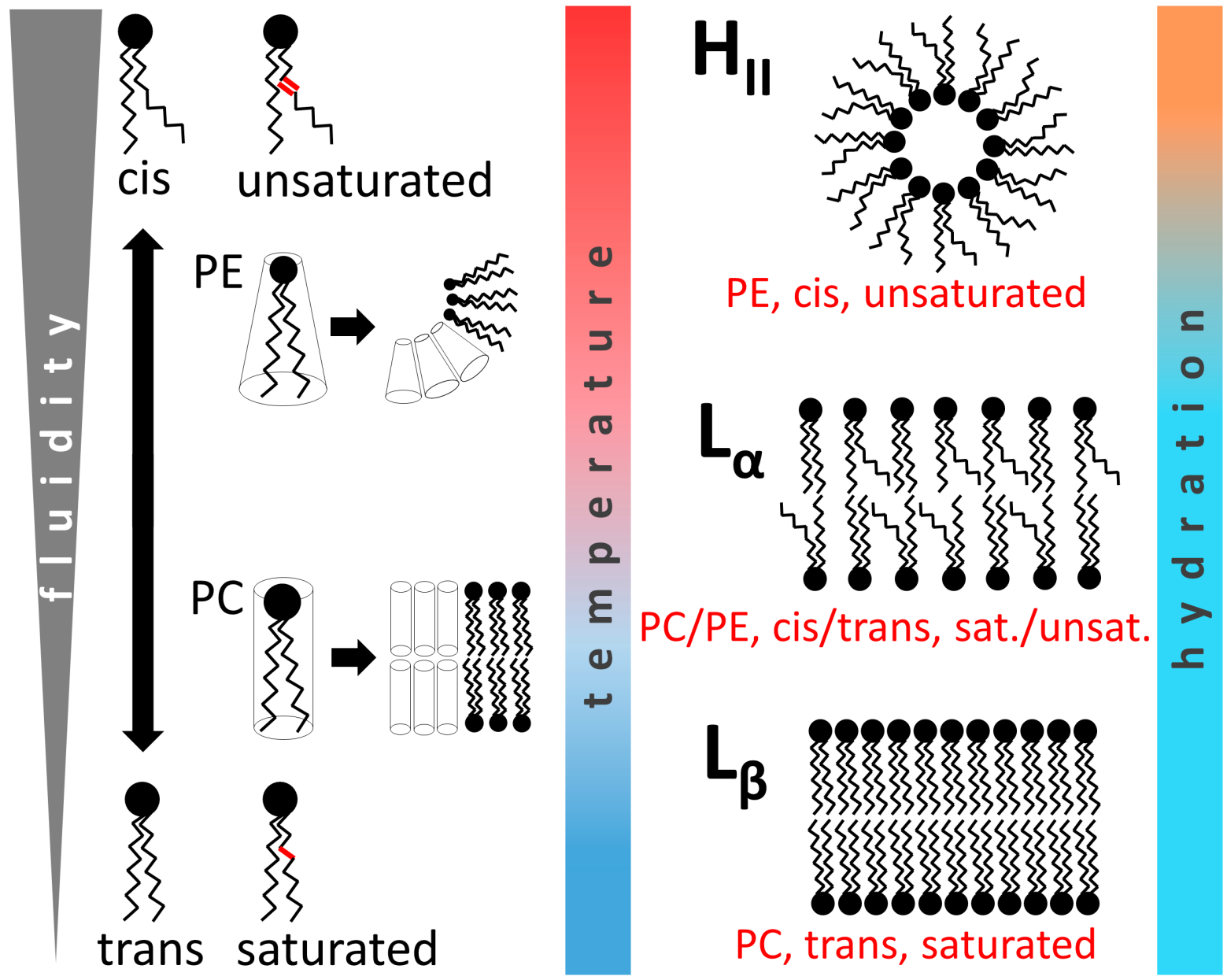

Fig. 3. Properties of biological membranes. The diagram shows how temperature, hydration and phospholipid composition affects the properties of biological membranes. PE - phosphatidylethanolamines; $P C$ - phosphatidylcholines; $L_{\alpha}$ - liquid crystalline phase; $L_{\beta}-$ gel phase; $\mathrm{H}_{\|}$- hexagonal phase; cis/trans - configuration of fatty acid chains; unsaturated/saturated - presence/absence of multiple bonds in fatty acid chains.

evidence of proteins surviving at low temperatures in-vivo. Štětina et al. (2020) report that citrate synthase from warm-acclimated larvae of the drosophilid fly Chymomyza costata shows near-normal function upon freezing at $-30^{\circ} \mathrm{C}$, although the larvae do not survive such treatment. Evidence exist for some enzymes also survive exposure to high temperatures. Heinrich at al. (2017) found that protein complexes of the mitochondrial electron transport chain of several insect species (Drosophila melanogaster, Culex pipiens, Tenebrio molitor, Acheta domesticus and Gromphadorhina portentosa) survive thermal death of the whole organism. As the insects studied by Štětina et al. (2020) and Heinrich at al. (2017) were reared under normal breeding conditions (they were "warm acclimated" and thus probably had no elevated levels of potentially protective compounds), one could speculate that the proteins studied may not require extra protection and physiological levels of protective compounds (normally present in the organism) can protect them from cold/heat denaturation. Storey \& Storey (1991) report that Glucose-6-phosphate dehydrogenase (G6PDH) extracted from Eurosta solidaginis and Epiblema scudderiana is fully protected from freezing at $-77^{\circ} \mathrm{C}$ by concentrations of cryoprotectants as low as 50
$\mathrm{mM}$. The fact that these insects were flash-frozen in liquid nitrogen and then stored at $-77^{\circ} \mathrm{C}$ prior to enzyme extraction makes the finding even more interesting. These examples raise questions about the role of proteins in cold injury: (1) How often is cold denaturation of proteins reversible? (2) Is potential cold-induced damage to proteins really a critical factor involved in cell/organism survival? and (3) Do (all) proteins really need extra protection against the effects of low/high temperatures?

Proteins are critical for metabolism as well as forming vital intracellular structures such as cytoskeleton. Coldinduced protein denaturation thus is a factor potentially affecting cell survival. However, despite the general belief that proteins are particularly vulnerable to damage by low temperatures and require relatively high concentrations of (cryo)protectants to protect them against cold denaturation, there is evidence that such a "rule" may not be universal and that at least some proteins may be resistant to cold denaturation under physiological conditions or they may denature reversibly.

\subsubsection{Biological membranes}

Biological membranes can also be damaged by low temperatures. Biological membranes (Fig. 3) consist of a phos- 
pholipid bilayer that also contains other molecules such as sterols, carbohydrates and embedded proteins. Similar to protein folding, biological membranes are formed by an aggregation of their components that occurs due to a hydrophobic effect when hydrophobic fatty acid chains are sequestered away from water and interact with each other inside the bilayer structure while hydrophilic headgroups are exposed on the membrane surface and interact with water molecules (Tanford, 1988).

Temperature is one of the main factors that influences the function of biological membranes through changes in fluidity. Temperature also affects membrane phase behaviour. Lipids in biological membranes may assume one of the three basic configurations (Fig. 3): (1) under optimal/“permissive" temperatures biological membranes exist in a fluid liquid crystalline phase $\left(\mathrm{L}_{\alpha}\right) ;(2)$ at temperatures lower than optimal/permissive, membrane may transition to a highly ordered gel phase $\left(\mathrm{L}_{\beta}\right)$; and (3) at temperatures higher than optimal/"permissive", a membrane may transition into a non-bilayer reversed hexagonal phase $\left(\mathrm{H}_{\mathrm{II}}\right)$ and loose its integrity (Chapman, 1975). The transition to the $\mathrm{H}_{\text {II }}$ phase may also occur at low hydration (Kirk et al., 1984), which may be relevant for freeze tolerant organisms and will be discussed in section 4 .

Membrane phase behaviour is also affected by phospholipid composition. For example, the two main classes of phospholipids, phosphatidylcholines (PC) and phosphatidylethanolamines (PE), have quite different effects on properties of biological membranes. At permissive temperatures, PC favour the formation of bilayer structures, while PE favour the formation of non-bilayer structures such as $\mathrm{H}_{\mathrm{II}}$. For each temperature range there is an optimal ratio of PC : PE, which can keep membrane fluid and functioning well (Hazel, 1995). The incorporation of components that do not form tight bi-layers, such as PEs, also facilitates integration of membrane proteins and local fluidity can even modulate the activity of membrane-associated proteins (de Kruijff, 1997; van Meer et al., 2008). Unregulated transition to $\mathrm{H}_{\mathrm{II}}$, on the other hand, may compromise membrane integrity. Other factors that affect membrane properties are the length of fatty acid chains and presence of multiple bonds within the constituent fatty acids in phospholipids when shorter fatty acid chains and multiple bonds contribute to higher membrane fluidity (Gennis, 1989). Changes in the PC:PE ratio as well as changes in the proportion of unsaturated fatty acids in phospholipid chains in membranes is a common acclimatory response of organisms (Košt’ál, 2010).

At temperatures optimal for formation and proper function of membranes, phospholipid molecules have more energy (compared to temperatures below optimal) and lipid chains may assume either a trans or cis configuration (Hazel, 1995). At optimal temperatures biological membranes are highly fluid, which results from their more disordered state (higher portion of cis) when lipids move faster, arranging and rearranging randomly. As temperature decreases, more lipids assume energetically favoured trans configuration and become more laterally ordered, which results in lower membrane fluidity. Membrane fluidity also influences the function of membrane associated enzymes as lipid-protein interactions affect protein conformation (McMurchie \& Raison, 1979; Lenaz, 1987). With decrease in temperature membrane thickness also increases as phospholipids become more organized (Kučerka et al., 2011). It is reported that hydrophobic mismatch (difference in the length of hydrophobic fatty acid chains between phospholipids and also between phospholipids and hydrophobic parts of membrane proteins; Fig. 4) influences the properties of membranes, with effects on membrane protein function (Killian, 1998; Wallace et al., 2006). The changes in membrane thickness, induced by temperature, are thus another factor potentially affecting the function of membranes and of membrane bound proteins (Hazel, 1989).

Probably the most common cause of membrane damage at low temperatures is the loss of the barrier function due to lateral phase separation (Hays et al., 2001; Tablin et al., 2001). When membranes reach the phase transition temperature, the membrane can transition from fluid to a gel phase (L $\beta)$, although this state would generally occur only in a membrane composed of a single class of phospholipids. Membranes of living organisms however, are composed of variety of classes of phospholipids and of other molecules that make membrane behaviour even more complex than simple models based on a single phospholipid class. At phase transition temperature only, a portion of a membrane may transition to the gel phase $\left(\mathrm{L}_{\beta}\right)$ while the rest remains in the fluid liquid crystalline phase $\left(\mathrm{L}_{\alpha}\right)$. The existence of two phases of phospholipids with different thicknesses in the same section of membrane causes a hydrophobic mismatch between the membrane components that can lead to lateral phase separation (Fig. 4) when separate domains of the fluid liquid crystalline phase $\left(\mathrm{L}_{\alpha}\right)$ and gel phase $\left(\mathrm{L}_{\beta}\right)$ coexist in close contact (Quinn, 1985; Wallace et al., 2006; Heberle \& Feigenson, 2011). The co-existence of phospholipid domains with different phases disrupts the function of a membrane as a semi-permeable barrier because at the interface of the two phases the membrane becomes leaky (Quinn, 1985; Mouritsen, 1991). In addition, the domains enriched with non-bilayer forming lipids (i.e. $\mathrm{L}_{\alpha}$; non-bilayer forming lipids move to $\mathrm{L}_{\alpha}$ domains during phase separation) may, after rewarming, form inverted $\mathrm{H}_{\mathrm{II}}$ structures within the bilayer, which compromise membrane integrity. Hydrophobic mismatch, lateral phase separation and related effects that directly compromise the functioning of the membrane as a barrier appear to be the most important causes of membrane low temperature damage.

Biological membranes can be damaged also by the formation of pores (Fig. 4). The main mechanism responsible for pore formation appears to be lateral tension (Karal \& Yamazaki, 2015; Akimov et al., 2017). When membrane tension reaches a critical level, a pore may form, which leads to the loss of semipermeable barrier function and leaking of solutes. The tension induced formation of pores in biological membranes could occur under freezing conditions when they are subject to mechanical stress caused by ice formation (for more details on the effects of ice forma- 


\section{Rupture}

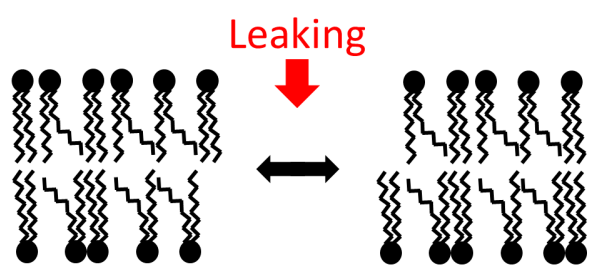

\section{Pore formation}

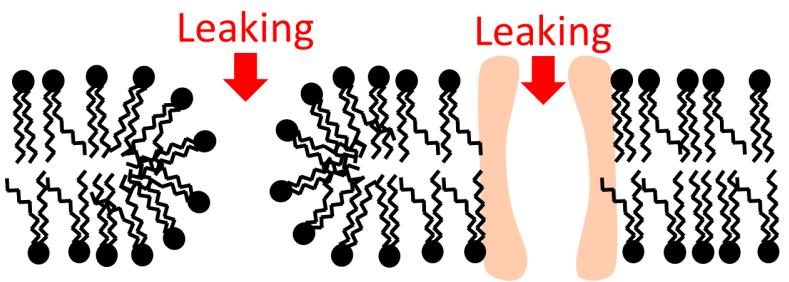

\section{Hydrophobic mismatch and phase separation}

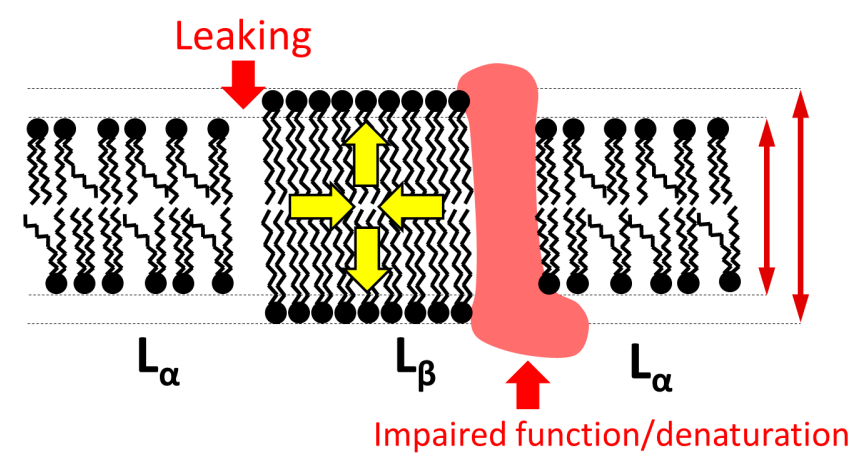

Fig. 4. Damage to biological membranes and membrane proteins. The diagram shows different kinds of damage to biological membranes and membrane proteins caused by low temperature/freezing. $\mathrm{L}_{\alpha}$ - liquid crystalline phase; $\mathrm{L}_{\beta}-$ gel phase. The pale orange object is a mitochondrial permeability transition pore. The pale red object is a membrane protein that may undergo conformational alterations due to hydrophobic mismatch, leading to impaired function or denaturation of the protein.

tion see section 4. Injury due to freezing). Another way a pore can form (specifically in the inner mitochondrial membrane) is via a so-called mitochondrial permeability transition pore (Fig. 4). Although the exact nature of these pores is still unknown (it is probably a multi-protein complex interacting with the membrane) (Halestrap, 2009; Carraro et al., 2020), it appears to be one of the main factors responsible for mitochondrial damage during reperfusion (reintroduction of oxygen after a period of hypoxia/ anoxia) and oxidative stress.

Another way in which membranes are damaged is by rupture, which may occur as a result of mechanical stress caused directly or indirectly by the formation of ice (membrane rupture is discussed in more detail in section 4. Injury due to freezing).

\subsubsection{Nucleic acids}

Nucleic acids are polymers composed of subunits bases. The bases polymerize into strands that form higher order structures such as a double helix. The conformation of the higher structures of nucleic acids is maintained by hydrogen bonds between complementary base pairs inside the structure. Perhaps an even more important factor contributing to stability of nucleic acids is the hydrophobic effect that stabilizes the structure from the outside (Feng et al., 2019). As already discussed in the case of proteins, the strength of these interactions (hydrogen bonds and hydrophobic effect) is temperature dependent and thus temperature is likely to influence the stability of the structure also in nucleic acids.
Although information on the mechanisms resulting in damage to nucleic acids by low temperatures is rather sparse in the literature, there is evidence that low temperatures affect the integrity of DNA and RNA. For example, there is evidence for possible DNA breaks in equine spermatozoa exposed to low temperatures $\left(-20^{\circ} \mathrm{C}\right)$ (Linfor \& Meyers, 2002), or degradation of RNA and also DNA in blood samples stored at low/freezing temperatures (Huang et al., 2017). There is also evidence for cold damage to DNA in insects (Lubawy et al., 2019). The effect of low temperatures on the structure of nucleic acids is best understood in ribozymes, specifically, hammerhead ribozyme . Hammerhead ribozyme catalyses reversible endonucleotic cleavage and ligation reactions at a specific site in RNA molecules in a variety of taxa, from viruses to mammals, including humans (Hammann et al., 2012). Mikulecky \& Feig (2002, 2004) analysed hammerhead ribozyme structure by means of circular dichroism spectroscopy and report an almost total loss of tertiary and secondary structures in the temperature range between $-10^{\circ} \mathrm{C}$ and $-30^{\circ} \mathrm{C}$. The spectra of the cold-denatured ribozymes resemble those of heat-denatured ribozymes. DNA denaturation by high temperatures occurs due to melting of double-stranded DNA, which separates into two single strands due to breaking of hydrogen bonds between bases in the duplex (Ussery, 2001). Some studies, however, indicate that oxidative stress could be a more important factor in DNA/RNA damage during cold exposure than low temperature and/or freezing alone (Tatone et al., 2010; Fraser et al., 2011). 
Although the mechanism by which nucleic acids are damaged by cold is not completely known it is possible that protein components (i.e. histones) of higher structures of DNA are also damaged by low temperatures. Damage to histones (even if reversible) could disturb the structure of chromatin and loosen DNA strands that could subsequently be more susceptible to denaturation and brakes.

\subsection{Effects of the rate of temperature change on cold injury}

The rate of temperature change (rates of cooling and warming) is another factor involved in cold injury in organisms. The damage to organisms by a rapid decline in temperature is termed "cold shock" (also "direct chilling injury" in plants). Cold shock appears to affect all cells, although there are probably differences in susceptibility between different types of cells (Watson \& Morris, 1987). The main factor responsible for damage due to cold shock is thought to be the transition of cell membranes to the gel phase (and consequent phase separation), which compromises the semipermeable barrier function and renders it leaky to solutes (Drobnis et al., 1993). Denaturation of proteins could also be involved in cold shock damage (Watson \& Morris, 1987).

Cooling rate also affects the formation of ice at freezing temperatures as rapid cooling results in the formation of small ice crystals (Bald, 1986; van der Sman, 2016). Rapid cooling, on the other hand, increases the risk of lethal intracellular freezing by promoting supercooling of intracellular solutions (Seki et al., 2009). Slow cooling enables cells to maintain osmotic equilibrium with freezing extracellular solutions and avoid intracellular freezing (Mazur, 1977). Rapid warming, on the other hand, is used to avoid recrystallization (see section 5 for more details on recrystallization) during thawing (Seki \& Mazur, 2008).

\section{INJURY DUE TO FREEZING}

Cold injury by freezing is (logically) a combination of the effects of low temperatures and of ice formation (Fig. 2). The effects of temperature on biological systems are discussed in previous paragraphs. The formation of ice may occur either outside cells (extracellular freezing) or inside cells (intracellular freezing). The effects of ice formation on cells and tissues can be divided into direct and indirect, based on the mechanism of damage (direct mechanical action of ice crystals vs. secondary effects, such as freeze dehydration and concentration of solutes).

\subsection{The freezing process}

When a solution (e.g. insect haemolymph) is cooled it does not necessarily freeze at its equilibrium melting point, but may remain liquid. A solution that remains in a liquid state at temperatures below its melting point is called supercooled. The supercooled state, however, is metastable and with decreasing temperature the probability of ice nucleation increases (Matsumoto et al., 2002). Ice nucleation can be either homogenous or heterogeneous, wherein homogenous nucleation occurs when a certain number of water molecules spontaneously form an ice lattice structure. In contrast, heterogeneous nucleation occurs on surfaces that can organize water molecules into an ice lattice, such as ice nucleating proteins or other heterogeneous nucleators - possibly dust particles (Zachariassen, 1992; Matsumoto et al., 2002). When an initial ice crystal (nucleus) reaches a critical mass, surrounding water molecules join it very rapidly, which can result in freezing of the remaining solution. The heat of crystallization released during freezing temporarily increases the temperature. Lowest temperature before freezing exotherm is released is the real freezing point (supercooling point, SCP) of the solution (Wilson et al., 2003; Sinclair et al., 2015). The extent of supercooling of a solution is affected by the volume (large volume = high probability of ice nucleation) of the solution, and also by the presence and concentration of solutes (solutes help to stabilize the supercooled state) and of potential ice nucleators (Lee, 1991; Lee et al., 1996; Zhao, 1997).

\subsection{Extracellular vs. intracellular freezing}

In organisms, freezing can be distinguished either as extracellular or intracellular.

Although intracellular freezing is considered almost invariably lethal for organisms, there is at least one example of survival of intracellular freezing at the organism level - the nematode Panagrolaimus davidi (Wharton \& Ferns, 1995). Survivable intracellular freezing is also reported occurring in some types of insect cells. Survival of intracellular freezing occurs for example in fat body cells of Eurosta solidaginis (Salt, 1962; Lee et al., 1993), Sarcophaga crassipalpis (Davis \& Lee, 2001) and Celatoblatta quinquemaculata (Worland et al., 2004).

The formation of intracellular ice osmotically drives water inside cells to join intracellular ice that might increase the mechanical stress on the cell membrane (i.e. swelling and subsequent rupture, Fig. 4). The intracellular ice may form either spontaneously (if cells are allowed to supercool enough) or it is seeded from outside the cell. Although the cell membrane is generally considered impermeable to ice, it has been shown that ice can propagate through pores in aquaporins (Seki et al., 2011) or through gap junctions (Acker et al., 2001). One possible route for ice penetration through cell membranes includes disruption of the membrane by exceeding a critical gradient in osmotic pressure across the membrane (Muldrew \& McGann, 1990). Another hypothesis assumes that ice can penetrate through membranes after the membrane is disrupted by an electric potential that may be induced at the waterice interface during freezing (Wolfe \& Bryant, 2001). For review/opinion on intracellular freezing in insects see Sinclair \& Renault (2010).

In most freeze tolerant organisms freezing is thought to be extracellular. Extracellular freezing leads to an increase in the concentration of extracellular fluids as solutes are excluded from ice lattices. The increased concentration of extracellular fluids osmotically draws water from cells (opposite to intracellular freezing). The cells shrink as they dehydrate and also the concentration of solutes in the intracellular fraction of unfrozen water increases (Storey \& Storey, 1988; Block, 2002). Both cellular freeze dehydra- 
tion and increased concentration of intracellular solutes can be harmful to cells, which is discussed in more detail in section 4.4 .

\subsection{Direct effects of ice formation}

Direct effects of ice formation are most likely the cause of damage at higher levels of organisation, such as, cellular and tissue. Damage occurs by direct mechanical action of ice crystals and increase in volume accompanying freezing, both extracellular and intracellular. In the case of intracellular freezing the mechanical forces exerted by growing intracellular ice (volumetric expansion) may cause cell membranes to rupture (Muldrew et al., 2004). In the case of extracellular freezing, the resulting cellular freeze dehydration may cause mechanical collapse of cells (cells shrink). Mazur and his colleagues (Mazur et al., 1981; Mazur \& Cole, 1985) propose that the reduction in the unfrozen fraction of water may be indirectly responsible for damage to cells. The proposed mechanism of damage is crushing of cells in the narrow liquid-filled spaces between masses of extracellular ice and forced cell to cell contacts. Although this concept was criticized at the time of publication, more recently it has been recognized as one of the possible causes of cellular damage by freezing (Pegg, 2010). There is more evidence in the literature, supporting mechanical damage to cells and tissues caused by growing ice crystals. Such evidence is reported, for example, in frozen liver sections (Frederik \& Busing, 1981), in suspensions of red blood cells (Ishiguro \& Rubinsky, 1994) and mechanical damage to cells and tissues by ice crystals is very well established also in "frozen foods research" literature (Petzold \& Aguilera, 2009; Kiani \& Sun, 2011). Mechanical damage by ice crystals also occurs during thawing through a process called recrystallization, which is discussed in section 5 .

\subsection{Indirect effects of ice formation}

Indirect effects of ice formation include mechanisms other than the direct mechanical action of ice crystals. Such mechanisms include the physico-chemical effects of ice formation, mostly freeze concentration of intracellular solutes and cellular freeze dehydration.

\subsubsection{Freeze concentration of solutes}

During extracellular freezing, water is osmotically drawn out of cells into extracellular ice that results in a potentially harmful increase in the concentration of intracellular solutes. Solutes can be distinguished as compatible (also referred to as kosmotropes or "structure making") and as incompatible (also referred to as chaotropes or "structure breaking"). The categorization is based on how the solute interacts with water molecules (Russo, 2008). In general, compatible solutes are predominantly hydrophilic molecules and ions that interact with water and form hydrogen bonds with water molecules. Incompatible solutes are predominantly hydrophobic, which reduces their interaction with water molecules. Incompatible solutes may cause damage to macromolecular structures by weakening the stabilizing hydrophobic effect and/or by directly interact- ing with hydrophobic parts of macromolecules that help to define their higher-order structure (Salvi et al., 2005). The compatible solutes, by interacting strongly with water molecules, can neutralize potentially dangerous hydrophobic particles (incompatible solutes) by decreasing their solubility in water and promoting these hydrophobic particles to aggregate with themselves rather than disrupting other macromolecules (Moelbert et al., 2004). Compatible solutes are preferentially excluded from the surface of macromolecules, thus preferentially hydrating (stabilizing) them, while incompatible solutes interact with macromolecules in a way that draws out their hydrophobic parts, thus destabilizing them (Timasheff, 2002; Shimizu \& Smith, 2004).

The effects of solutes on biological systems depends on their quality and quantity (concentration), and these interactions are also affected by temperature (Moelbert \& De Los Rios, 2003). Molecules with both hydrophilic and hydrophobic residues may act as both compatible and incompatible solutes depending on temperature and their concentration. At low temperatures and/or low concentrations these molecules act as compatible solutes (cryoprotectants) and stabilize macromolecules. At high temperatures and/or high concentrations the hydrophobic nature of such molecules predominates and they act as incompatible solutes, destabilizing macromolecules. These properties are driven by a hydrophobic effect that is strongest at high temperatures (and weakest at low temperatures), and on the effect of these molecules on tension and dielectric properties of water (for more details see Arakawa et al., 1990; Elliott et al., 2017). A molecule that "normally" acts as cryoprotectant may, thus upon reaching a certain concentration (e.g. during freeze dehydration) or during rewarming, become toxic and cause damage to macromolecules. Typical examples of such molecules are ethylene glycol and dimethyl sulfoxide (DMSO) (Arakawa et al., 1990). As for biologically more relevant molecules, for example, the amino acid proline appears to have similar qualities (Verbruggen \& Hermans, 2008). Evidence exists also for some cryoprotectants and their mixtures acting as pro-oxidants at high concentrations, causing (although probably indirectly) oxidative damage to biological membranes and proteins (Best, 2015).

\subsubsection{Freeze dehydration}

Freeze dehydration is believed to be one of the main causes of freezing injury in organisms. However, when compared with the more severe dehydration by drying, its role appears rather unclear, at least in terms of macromolecular damage. The water in cells can be distinguished as either osmotically active (OAW) or as osmotically inactive (OIW). The OAW (also referred to as "free water" or "freezable water") is the fraction of water that can freeze or can be lost through desiccation/drying. The OIW (also referred to as "hydration water", "bound water", or "unfreezable water") is the water that constitutes the hydration shells of macromolecules (and solvents) and enables their normal functioning by maintaining their functional conformation (Ball, 2008; Brovchenko \& Oleinikova, 2008). Loss of hydration water thus may have serious consequences for 
the structure and function of macromolecules (Crowe et al., 1990). The fraction of OIW however, under normal conditions (temperatures and pressures normally occurring in biosphere), does not freeze (Crowe et al., 1990, Wolfe et al., 2002). Freeze dehydration therefore must be significantly different from dehydration by drying (desiccation), where a significant portion of the OIW can be removed (Dolman et al., 1997). In the light of the "unfreezable" nature of OIW, it is thus questionable how significant the role of freeze dehydration per se is in causing damage to macromolecules. Whether or not freeze dehydration is a critical factor for the structure of at least some macromolecules, freezing of a portion of body water may cause damage to organisms. Some insects and also other organisms die as soon as certain portion of OAW freezes (Rozsypal \& Košt’ál, 2018). This suggests that even partial removal of OAW (partial dehydration without actually "touching" the OIW) may cause damage.

Dehydration appears to have the most profound effects on biological membranes that may be damaged as soon as OAW (or significant portion of OAW) is removed (GordonKamm \& Steponkus, 1984). Interestingly, computer simulations of membranes suggest that partial removal of OIW is required to significantly affect the integrity of biological membranes (Marrink \& Mark, 2004). In other words, simulations suggest that freezing/removal of OAW should not disrupt biological membranes, although experiments on real membranes show that it does. Under low hydration biological membranes are more susceptible to phase transition to the inverted hexagonal phase $\left(\mathrm{H}_{\mathrm{II}}\right)$, which may lead to irreversible loss of the barrier function of membranes (Crowe \& Crowe, 1987). However, as mentioned above, it remains unclear if dehydration that occurs during freezing is sufficient to disrupt the hydration shells of macromolecules to cause damage. Simulations of water behaviour in biological systems suggest that OIW is very difficult to remove by freezing. Although OIW eventually freezes, the freezing process is supposed to take a significant amount of time, perhaps even a human life-time or longer (Wolfe et al., 2002).

Less severe levels of cellular freeze dehydration can be damaging, mostly at cellular level through membrane fusions (Crowe \& Crowe, 1982), which can even compromise the viability of cells. A hypothesis of Steponkus $\&$ Wiest (1978) assumes that freeze dehydration induces membrane fusions that may reduce the membrane area (as dehydrated cells shrink, their membranes become "wrinkled" and close contact between the wrinkles may result in membrane fusions, reducing the membrane area). Then, during rehydration, the membrane may rupture because it can no longer accommodate the original amount of water. Thus, although the causes of damage occur during freezing, the damage per se occurs during thawing.

Membrane rupture, however, may occur even without membrane fusions. Muldrew et al. (2000) assume that exposure of a cell to a hypertonic solution (i.e. during extracellular freezing) leads to uptake of ions that may, during thawing, cause the cell to swell beyond its elastic limits and consequently rupture. Cells must accommodate more water than the original amount in order to be in osmotic equilibrium with an extracellular solution. Different causes of membrane rupture are proposed by the "Osmotic rupture hypothesis" (Muldrew \& McGann, 1994). The Osmotic rupture hypothesis assumes that during rapid extracellular freezing the osmotically driven water efflux from cells exerts friction on membranes, which may result in membrane rupture (and eventually in intracellular freezing).

Dehydration, on the other hand, appears to have less serious consequences for the structure and function of proteins. Although dehydration may cause proteins to denature, denaturation in proteins is reversible and many proteins can regain their functional conformation upon rehydration (Prestrelski et al., 1993).

\section{INJURY DURING THAWING AND POST-THAW}

Whether it occurs naturally or under controlled laboratory conditions, freezing is eventually followed by thawing. In the previous paragraphs the mechanisms of cold injury due to low temperatures and freezing are discussed. However, cold injury also may occur or become manifest during thawing and post-thaw. One of the mechanisms of damage during thawing is recrystallization when large ice crystals grow at the expense of smaller ice crystals (Hartel, 1998). Recrystallization may occur during longer exposures to constant temperatures, but recrystallization is most pronounced during repeated cycles of partial melting and refreezing. Recrystallization causes damage by direct mechanical action of growing ice crystals and could affect the survival of organisms exposed to freeze-thaw events (Lee, 1991). Recrystallization is also an important limiting factor in successful cryopreservation (Meryman, 2007; Pegg, 2010) and significantly affects the quality of frozen foods, such as animal and plant tissues (Martino \& Zaritzky, 1988; Ullah et al., 2014).

Another significant factor involved in cold injury during thawing is osmotic stress that is caused by differences in the concentrations of intracellular and extracellular solutes that occurs during both freezing and thawing. As discussed in section 4.2., during freezing, the increased concentration of extracellular fluids osmotically draws water from cells into extracellular ice. The processes are reversed during thawing, meaning that water is drawn from extracellular spaces back into cells. Osmotic stress during thawing could compromise the integrity of the cell membrane, as discussed in the previous section.

Disruption of ionic balance through reduced/no active transport (caused by impaired function of membrane proteins) at low and/or freezing temperatures may result in cell membrane depolarization. Loss of the trans-membrane potential can lead to the opening of ion channels and subsequent increase in the cytosolic concentration of $\mathrm{Ca}^{2+}$. Then, $\mathrm{Ca}^{2+}$ can activate enzymes responsible for cell death and thus eventually apoptosis or necrosis (Yu et al., 2001; Lang et al., 2005; Bayley et al., 2018; Overgaard et al., 2021). Although disruption of the ionic balance could be a significant cause of cold and freezing injury, some cold tolerant 
insects (and probably also other cold tolerant organisms) can restore trans-membrane potentials relatively quickly after thawing and thus avoid the negative effects of losing ionic balance (Kristiansen \& Zachariassen, 2001; Boardman et al., 2011).

Another cause of injury (especially during thawing and post-thaw) is oxidative stress. The metabolism of cold tolerant insects and other organisms exposed to low temperatures (including supercooling and freezing conditions) is slower but it does not cease completely (Irwin \& Lee, 2002). The suppressed metabolism continues to consume energy and may produce reactive oxygen species (Lalouette et al., 2011), which can cause oxidative damage. In a frozen state, the availability of oxygen is restricted, resulting in hypoxia (ischemia) and an accumulation of products of anaerobic metabolism. During thawing and/ or post-thaw, oxygen is reintroduced to cells (reperfusion). The sudden increase in the availability of oxygen leads to a burst of mitochondrial activity and production of reactive oxygen species (ROS) by the mitochondrial electron transport chain (Du et al., 1998). Molecular oxygen is converted to superoxide and other reactive forms of oxygen. The build-up of reactive oxygen species and other prooxidants, such as lipid peroxides, can then cause oxidative damage to numerous macromolecular structures (for a review on oxidative damage due to freezing in insects see Storey \& Storey, 2010).

\section{CONCLUSIONS AND FUTURE DIRECTIONS}

Temperature, through its systemic effect, appears to play a major role in cold injury in organisms by directly affecting the structure and function of macromolecules. Cold injury by freezing results from both the effect of low temperatures and of ice formation. The formation of ice causes injury either directly by mechanical forces exerted by growing ice crystals or indirectly through various physico-chemical effects. The indirect effects of ice formation include osmotic stress, increased concentration of solutes and cellular freeze dehydration. Cold injury also occurs during thawing by recrystallization, disruption of ionic balance and oxidative stress upon reintroduction of oxygen to the organism.

The present review shows that cold injury occurs as a result of the interaction of many factors during cold exposure and/or the freeze-thaw cycle. The damage basically affects only three kinds of macromolecular structures: proteins, nucleic acids and biological membranes. The molecular nature of cold injury implies that damage may occur anywhere and everywhere within an organism (to the macromolecules) and then cascade up to the cellular, tissue and eventually organismal level.

Although the molecular mechanisms of cold injury are basically known, there are gaps to be filled in our understanding of the nature of cold injury in organisms. For example, the nature of cold/freezing damage to nucleic acids is not well understood. The role of freeze dehydration (which is significantly different from desiccation) in cold/freezing injury, although frequently cited as fact in insect literature, is also unclear. The role of proteins in cold/freezing injury also appears to be problematic. Some findings even suggest that molecular and organismal injury may not be related, at least in the case of proteins, as quite a few enzymes are reported to survive cold/freezing death of whole organisms. While some proteins may denature reversibly, other proteins appear to be resistant to low temperatures and/or freezing while protected "only" by physiological concentrations of cryoprotectants or by concentrations even much lower than physiological. Thus, one could ask are there any proteins that denature irreversibly at low temperatures under physiological concentrations of metabolites? If proteins do not require extra protection, why do many organisms accumulate such high levels of cryoprotectants? Is it to protect biological membranes and/ or DNA? Last but not least, it is also not well understood how damage to macromolecules cascades up and affects higher levels of organization.

Research on the most fundamental physico-chemical principles of cold injury at the molecular and perhaps even atomic levels appears rather beyond the reach of biological disciplines and may be better left to biophysicists. Biologists on the other hand may focus on testing the anticipated roles of known mechanisms in cold injury and cryoprotection at higher levels of organization but, to an extent, also at the molecular level. So how can research in the field of insect environmental physiology and cold tolerance contribute to filling the gaps in our knowledge on the causes of cold injury? For example, activity measurements of various enzymes from a variety of species cooled/frozen under different conditions and concentrations of cryoprotectants could shed more light on the role of proteins (enzymes) and of cryoprotectants in cold injury in organisms. Damage but also protection of biological membranes can be assessed for example by dye exclusion assays. Comet assay can be used to assess the integrity of DNA after cold/freezing stress. Differential scanning calorimetry, by measuring the amount of osmotically active and inactive water and fraction of ice within organisms, can contribute to a better understanding of the effects of freeze dehydration in cold injury. Another way to contribute to a better understanding of the nature of cold injury in organisms could be the integration of new knowledge acquired in the field of biophysics (which is not always easy to understand for a biologist) to biological disciplines and vice versa, from which both fields could benefit.

Research on the mechanisms of cold injury in organisms is likely to take a long time. Although our understanding of the mechanisms of cold injury in organisms has greatly improved over the past few decades, many gaps in our knowledge remain to be filled. Better understanding of the nature of cold injury in organisms is important and may aid, for example, the development of techniques that will enable cryopreservation of not only cells but also tissues, organs and eventually perhaps even whole organisms.

ACKNOWLEDGEMENTS. This work was supported by the Czech Science Foundation (GAČR) grant no. 19-13381S and by institutional budget of the Institute of Entomology, Biology Centre of 
the Czech Academy of Sciences. I thank the reviewers and my colleagues for their valuable comments and suggestions.

\section{REFERENCES}

AcKer J.P., Elliott J.A.W. \& McGanN L.E. 2001: Intercellular ice propagation: experimental evidence for ice growth through membrane pores. - Biophys. J. 81: 1389-1397.

Akimov S.A., Volynsky P.E., Galimzyanov T.R., Kuzmin P.I., Pavlov K.V. \& BatishcheV O.V. 2017: Pore formation in lipid membrane II: Energy landscape under external stress. - Sci. Rep. 7: 12509, 21 pp.

Arakawa T., Carpenter J.F., Kita Y.A. \& Crowe J.H. 1990: The basis for toxicity of certain cryoprotectants: a hypothesis. Cryobiology 27: 401-415.

BALD W.B. 1986: On crystal size and cooling rate. - J. Microsc. 143: 89-102.

BALL P. 2008: Water as an active constituent in cell biology. Chem. Rev. 108: 74-108.

Bayley J.S., Winther C.B., Andersen M.K., GrønKJer C., Nielsen O.B., Pedersen T.H. \& Overgaard J. 2018: Cold exposure causes cell death by depolarization-mediated $\mathrm{Ca} 2+$ overload in a chill-susceptible insect. - Proc. Natn. Acad. Sci. USA 115: E9737-E9744.

Best B.P. 2015: Cryoprotectant toxicity: Facts, issues, and questions. - Rejuvenation Res. 18: 422-436.

BLOCK W. 2002: Interactions of water, ice nucleators and desiccation in invertebrate cold survival. - Eur. J. Entomol. 99: 259-266.

Boardman L., Terblanche J.S. \& Sinclair B.J. 2011: Transmembrane ion distribution during recovery from freezing in the woolly bear caterpillar Pyrrharctia isabella (Lepidoptera: Arctiidae). - J. Insect Physiol. 57: 1154-1162.

Boychuk E.C., Smiley J.T., Dahlhoff E.P., Bernards M.A., Rank N.E. \& Sinclair B.J. 2015: Cold tolerance of the montane Sierra leaf beetle, Chrysomela aeneicollis. - J. Insect Physiol. 81: 157-166.

Brovchenko I. \& Oleinikova A. 2008: Which properties of spanning network of hydration water enable biological functions? - ChemPhysChem 9: 2695-2702.

Carraro M., Carrer A., Urbani A. \& Bernardi P. 2020: Molecular nature and regulation of the mitochondrial permeability transition pore(s), drug target(s) in cardioprotection. - J. Mol. Cell. Cardiol. 144: 76-86.

Chapman D. 1975: Phase transitions and fluidity characteristics of lipids and cell membranes. - Q. Rev. Biophys. 8: 185-235.

Chi E.Y., Krishnan S., Randolph T.W. \& Carpenter J.F. 2003: Physical stability of proteins in aqueous solution: mechanism and driving forces in nonnative protein aggregation. - Pharm. Res. 20: 1325-1336.

Clark M.S. \& Worland M.R. 2008: How insects survive the cold: molecular mechanisms-a review. - J. Comp. Physiol. (B) 178: 917-933.

Colinet H., Lee S.F. \& Hoffmann A. 2010: Temporal expression of heat shock genes during cold stress and recovery from chill coma in adult Drosophila melanogaster. - FEBS J. 277: 174-185.

Crowe J.H. \& Crowe L.M. 1982: Hydration-dependent hexagonal phase lipid in a biological membrane. - Arch. Biochem. Biophys. 217: 582-587.

Crowe L.M. \& Crowe J.H. 1987: Effects of water and carbohydrates on membrane fluidity. In Aloia R.C., Curtain C.C. \& Gordon L.M. (eds): Physiological Regulation of Membrane Fluidity. A.R. Liss, New York, pp. 75-100.
Crowe J.H., Carpenter J.F., Crowe L.M. \& Anchordoguy T.J. 1990: Are freezing and dehydration similar stress vectors? A comparison of modes of interaction of stabilizing solutes with biomolecules. - Cryobiology 27: 219-231.

Das U., Hariprasad G., Ethayathulla A.S., Manral P., Das T.K., Pasha S., Mann A., Ganguli M., Verma A.K., Bhat R. et AL. 2007: Inhibition of protein aggregation: Supramolecular assemblies of arginine hold the key. - PLOS ONE 2: e1176, 9 pp.

DAVIS D.J. \& LEE R.E. 2001: Intracellular freezing, viability, and composition of fat body cells from freeze-intolerant larvae of Sarcophaga crassipalpis. - Arch. Insect Biochem. Physiol. 48: 199-205.

DE KRUIJFF B. 1997: Lipid polymorphism and biomembrane function. - Curr. Opin. Chem. Biol. 1: 564-569.

Des Marteaux L.E., Štětina T. \& KoŠŤÁL V. 2018: Insect fat body cell morphology and response to cold stress is modulated by acclimation. - J. Exp. Biol. 221: jeb189647, 8 pp.

Dias C.L., Ala-Nissila T., Wong-EkKabut J., Vattulainen I., Grant M. \& KartTunen M. 2010: The hydrophobic effect and its role in cold denaturation. - Cryobiology 60: 91-99.

Dill K.A., Truskett T.M., Vlachy V. \& Hribar-Lee B. 2005: Modeling water, the hydrophobic effect, and ion solvation. Annu. Rev. Biophys. Biomol. Struct. 34: 173-199.

Dolman M., Halling P.J., Moore B.D. \& Waldron S. 1997: How dry are anhydrous enzymes? Measurement of residual and buried 180-labeled water molecules using mass spectrometry. Biopolymers 41: 313-332.

Drobnis E.Z., Crowe L.M., Berger T., Anchordoguy T.J., OverStreet J.W. \& Crowe J.H. 1993: Cold shock damage is due to lipid phase transitions in cell membranes: A demonstration using sperm as a model. - J. Exp. Zool. 265: 432- 437.

Du G., Mouithys-Mickalad A. \& Sluse F.E. 1998: Generation of superoxide anion by mitochondria and impairment of their functions during anoxia and reoxygenation in vitro. - Free Radic. Biol. Med. 25: 1066-1074.

Elliott G.D., Wang S. \& Fuller B.J. 2017: Cryoprotectants: a review of the actions and applications of cryoprotective solutes that modulate cell recovery from ultra-low temperatures. Cryobiology 76: 74-91.

Feng B., Sosa R.P., MÅrtensson A.K., Jiang K., Tong A., Dorfman K.D., Takahashi M., Lincoln P., Bustamante C.J. \& Westerlund F. 2019: Hydrophobic catalysis and a potential biological role of DNA unstacking induced by environment effects. - Proc. Natn. Acad. Sci. USA 116: 17169-17174.

FRANKS F. 1995: Protein destabilization at low temperatures. Adv. Protein Chem. 46: 105-139.

Franks F. \& Hatley R.H.M. 1991: Stability of proteins at subzero temperatures: thermodynamics and some ecological consequences. - Pure Appl. Chem. 63: 1367-1380.

Fraser L., Strzezek J. \& Kordan W. 2011: Effect of freezing on sperm nuclear DNA. - Reprod. Domest. Anim. 46: 14-17.

FrederiK P.M. \& Busing W.M. 1981: Ice crystal damage in frozen thin sections: freezing effects and their restoration. - J. Microsc. 121: 191-199.

GAO D. \& CRITSER J.K. 2000: Mechanisms of cryoinjury in living cells. - ILAR J. 41: 187-196.

GENNIS R.B. 1989: Biomembranes. Molecular Structure and Function. Springer, New York, 533 pp.

Gilbert N. \& Raworth D.A. 1996: Insects and temperature - a general theory. - Can. Entomol. 128: 1-13.

Gordon-Kamm W.J. \& Steponkus P.L. 1984: Lamellar-to-hexagonal $_{\mathrm{II}}$ phase transitions in the plasma membrane of isolated protoplasts after freeze-induced dehydration. - Proc. Natn. Acad. Sci. USA 81: 6373-6377. 
HALESTRAP A.P. 2009: What is the mitochondrial permeability transition pore? - J. Mol. Cell. Cardiol. 46: 821-831.

Hammann C., Luptak A., Perreault J. \& de la Peña M. 2012 The ubiquitous hammerhead ribozyme. - RNA 18: 871-885.

HARTEL R.W. 1998: Mechanisms and kinetics of recrystallization in ice cream. In Reid D.S. (ed.): The Properties of Water in Foods ISOPOW 6. Springer, Boston, pp. 287-319.

Hays L.M., Crowe J.H., Wolkers W. \& Rudenko S. 2001: Factors affecting leakage of trapped solutes from phospholipid vesicles during thermotropic phase transitions. - Cryobiology 42: $88-102$.

HAZEL J.R. 1989: Cold adaptation in ectotherms: Regulation of membrane function and cellular metabolism. In Wang L.C.H. (ed.) Animal Adaptation to Cold. Advances in Comparative and Environmental Physiology, Vol. 4. Springer, Berlin, Heidelberg, pp. 1-50.

Hazel J.R. 1995: Thermal adaptation in biological membranes: Is homeoviscous adaptation the explanation? - Annu. Rev. Physiol. 57: 19-42.

Heberle F.A. \& Feigenson G.W. 2011: Phase separation in lipid membranes. - Cold Spring Harb. Perspect. Biol. 3: a004630, $13 \mathrm{pp}$.

Heinrich E.C., Gray E.M., Ossher A., Meigher S., Grun F. \& BRADLEY T.J. 2017: Aerobic function in mitochondria persists beyond death by heat stress in insects. $-J$. Therm. Biol. 69: 267-274.

Huang L.-H., Lin P.-H., Tsai K.-W., Wang L.-J., Huang Y.-H., Kuo H.-C. \& Li S.-C. 2017: The effects of storage temperature and duration of blood samples on DNA and RNA qualities. PLoS ONE 12: e0184692, 13 pp.

IrWIN J.T. \& LeE R.E. 2002: Energy and water conservation in frozen vs. supercooled larvae of the goldenrod gall fly, Eurosta solidaginis (Fitch) (Diptera: Tephritidae). - J. Exp. Zool. 292: $345-350$.

IsHIGURO H. \& RUBINSKY B. 1994: Mechanical interactions between ice crystals and red blood cells during directional solidification. - Cryobiology 31: 483-500.

KARAL M.A.S. \& YAMAZAKI M. 2015: Communication: Activation energy of tension-induced pore formation in lipid membranes. - J. Chem. Phys. 143: 081103, 5 pp.

KARShIKOFF A., NilsSON L. \& LADENSTEIN R. 2015: Rigidity versus flexibility: the dilemma of understanding protein thermal stability. - FEBS J. 282: 3899-3917.

KaYUKaWA T. \& IshiKawa Y. 2009: Chaperonin contributes to cold hardiness of the onion maggot Delia antiqua through repression of depolymerization of actin at low temperatures. - PLoS ONE 4: e8277, 7 pp.

KIANI H. \& SUN D.W. 2011: Water crystallization and its importance to freezing of foods: A review. - Trends Food Sci. Technol. 22: 407-426.

KiLLIAN J.A. 1998: Hydrophobic mismatch between proteins and lipids in membranes. - Biochim. Biophys. Acta 1376: 401416.

KirK G.L., Gruner S.M. \& STEIN D.L. 1984: A thermodynamic model of the lamellar to inverse hexagonal phase transition of lipid membrane-water systems. - Biochemistry 23: 10931102 .

KošŤÁL V. 2010: Cell structural modifications in insects at low temperatures. In Denlinger D.L. \& Lee R.E. (eds): Low Temperature Biology of Insects. Cambridge University Press, Cambridge, pp. 116-140.

KošŤÁl V., Renault D., Mehrabianová A. \& Bastl J. 2007 Insect cold tolerance and repair of chill-injury at fluctuating thermal regimes: Role of ion homeostasis. - Comp. Biochem. Physiol. (A) 147: 231-238.
KoŠŤÁL V., Grgac R. \& Korbelová J. 2019: Delayed mortality and sublethal effects of cold stress in Drosophila melanogaster. - J. Insect Physiol. 113: 24-32.

KristianSEN E. \& ZACHARIASSEN K.E. 2001: Effect of freezing on the transmembrane distribution of ions in freeze-tolerant larvae of the wood fly Xylophagus cinctus (Diptera, Xylophagidae). - J. Insect Physiol. 47: 585-592.

KuČERKA N., Nieh M.-P. \& Katsaras J. 2011: Fluid phase lipid areas and bilayer thicknesses of commonly used phosphatidylcholines as a function of temperature. - Biochim. Biophys. Acta (Biomembr.) 1808: 2761-2771.

KunUGi S. \& TANAKA N. 2002: Cold denaturation of proteins under high pressure. - Biochim. Biophys. Acta 1595: 329-344.

Lalouette L., Williams C.M., Hervant F., Sinclair B.J. \& ReNAULT D. 2011: Metabolic rate and oxidative stress in insects exposed to low temperature thermal fluctuations. - Comp. Biochem. Physiol. (A) 158: 229-234.

Lang F., Föller M., Lang K.S., Lang P.A., Ritter M., Gulbins E., Vereninov A. \& Huber S.M. 2005: Ion channels in cell proliferation and apoptotic cell death. $-J$. Membr. Biol. 205: 147-157.

LeE R.E. 1991: Principles of insect low temperature tolerance. In Lee R.E. \& Denlinger D.L. (eds): Insects at Low Temperature. Chapman and Hall, New York, pp. 17-46.

Lee R.E., McGrath J.J., Morason R.T. \& Taddeo R.M. 1993: Survival of intracellular freezing, lipid coalescence and osmotic fragility in fat body cells of the freeze-tolerant gall fly Eurosta solidaginis. - J. Insect Physiol. 39: 445-450.

Lee R.E., Costanzo J.P. \& Mugnano J.A. 1996: Regulation of supercooling and ice nucleation in insects. - Eur. J. Entomol. 93: 405-418.

LENAZ G. 1987: Lipid fluidity and membrane protein dynamics. - Biosci. Rep. 7: 823-837.

LevitT J. 1980: Responses of Plants to Environmental Stresses. Vol. 1. Chilling, Freezing, and High Temperature Stresses. Academic Press, London, $497 \mathrm{pp}$.

Linfor J.J. \& Meyers S.A. 2002: Detection of DNA damage in response to cooling injury in equine spermatozoa using singlecell gel electrophoresis. - J. Androl. 23: 107-113.

Lubawy J., Daburon V., Chowański S., SŁocińska M. \& Colinet H. 2019: Thermal stress causes DNA damage and mortality in a tropical insect. - J. Exp. Biol. 222: jeb213744, 9 pp.

MacMillan H.A. 2019: Dissecting cause from consequence: a systematic approach to thermal limits. - J. Exp. Biol. 222: jeb191593, 8 pp.

MacMillan H.A. \& SinClair B.J. 2011: Mechanisms underlying insect chill-coma. - J. Insect Physiol. 57: 12-20.

MacMillan H.A. \& OvergaARD J. 2017: The integrative physiology of insect chill tolerance. - Annu. Rev. Physiol. 79: 187208.

MARRINK S.J. \& MARK A.E. 2004: Molecular view of hexagonal phase formation in phospholipid membranes. - Biophys. $J$. 87: $3894-3900$.

Marshall K.E. \& Sinclair B.J. 2011: The sub-lethal effects of repeated freezing in the woolly bear caterpillar Pyrrharctia isabella. - J. Exp. Biol. 214: 1205-1212.

MARTINO M.N. \& ZARITZKY N.E. 1988: Ice crystal size modifications during frozen beef storage. - J. Food Sci. 53: $1631-$ 1637.

Matsumoto M., Saito S. \& Ohmine I. 2002: Molecular dynamics simulation of the ice nucleation and growth process leading to water freezing. - Nature 416: 409-413.

Mazur P. 1969: Freezing injury in plants. - Annu. Rev. Plant Physiol. 20: 419-448. 
MAzuR P. 1977: The role of intracellular freezing in the death of cells cooled at supraoptimal rates. - Cryobiology 14: 251272.

MAZuR P. \& Cole K.W. 1985: Influence of cell concentration on the contribution of unfrozen fraction and salt concentration to the survival of slowly frozen human erythrocytes. - Cryobiology 22: 509-536.

Mazur P., Rall W.F. \& Rigopoulos N. 1981: Relative contributions of the fraction of unfrozen water and of salt concentration to the survival of slowly frozen human erythrocytes. - Biophys. J. 36: 653-675.

McMurchie E.J. \& Raison J.K. 1979: Membrane lipid fluidity and its effect on the activation energy of membrane-associated enzymes. - Biochim. Biophys. Acta (Biomembr.) 554: 364374.

Meryman H.T. 1974: Freezing injury and its prevention in living cells. - Annu. Rev. Biophys. Bioeng. 3: 341-363.

Meryman H.T. 2007: Cryopreservation of living cells: principles and practice. - Transfusion 47: 935-945.

Michaud M.R., Benoit J.B., Lopez-Martinez G., Elnitsky M.A., Lee R.E. \& Denlinger D.L. 2008: Metabolomics reveals unique and shared metabolic changes in response to heat shock, freezing and desiccation in the Antarctic midge, Belgica antarctica. - J. Insect Physiol. 54: 645-655.

Mikulecky P.J. \& Feig A.L. 2002: Cold denaturation of the hammerhead ribozyme. - J. Am. Chem. Soc. 124: 890-891.

Mikulecky P.J. \& Feig A.L. 2004: Heat capacity changes in RNA folding: application of perturbation theory to hammerhead ribozyme cold denaturation. - Nucleic Acids Res. 32: 3967-3976.

Moelbert S. \& De Los Rios P. 2003: Hydrophobic interaction model for upper and lower critical solution temperatures. Macromolecules 36: 5845-5853.

Moelbert S., Normand B. \& De Los Rios P. 2004: Kosmotropes and chaotropes: modelling preferential exclusion, binding and aggregate stability. - Biophys. Chem. 112: 45-57.

Mouritsen O.G. 1991: Theoretical models of phospholipid phase transitions. - Chem. Phys. Lipids 57: 179-194.

MuldRew K. \& McGanN L.E. 1990: Mechanisms of intracellular ice formation. - Biophys. J. 57: 525-532.

MuldRew K. \& McGanN L.E. 1994: The osmotic rupture hypothesis of intracellular freezing injury. — Biophys. J. 66: 532-541.

Muldrew K., Acker J.P. \& WAN R. 2000: Investigations into quantitative post-hypertonic lysis theory using cultured fibroblasts. - Cryobiology 41: 337.

Muldrew K., Acker J.P., Elliott J.A.W. \& McGann L.E. 2004: The water to ice transition: Implications for living cells. In: Fuller B.J., Lane N. \& Benson E.E. (eds): Life in the Frozen State. CRC Press, Boca Raton, pp. 67-108.

OvergaARd J. \& Macmillan H.A. 2017: The integrative physiology of insect chill tolerance. - Annu. Rev. Physiol. 79: 187208.

OvergaArd J., Gerber L. \& Andersen M.K. 2021: Osmoregulatory capacity at low temperature is critical for insect cold tolerance. - Curr. Opin. Insect Sci. 47: 38-45.

PEGG D.E. 2010: The relevance of ice crystal formation for the cryopreservation of tissues and organs. - Cryobiology 60: 36-44.

Peña F.J., Macías García B., Samper J.C., Aparicio I.M., Tapia J.A. \& Ortega Ferrusola C. 2011: Dissecting the molecular damage to stallion spermatozoa: The way to improve current cryopreservation protocols? - Theriogenology 76: 1177-1186.

Petzold G. \& Aguilera J.M. 2009: Ice morphology: Fundamentals and technological applications in foods. - Food Biophys. 4: $378-396$.
Prestrelski S.J., Tedeschi N., Arakawa T. \& Carpenter J.F. 1993: Dehydration-induced conformational transitions in proteins and their inhibition by stabilizers. - Biophys. J. 65: 661-671.

Privalov P.L. 1990: Cold denaturation of proteins. - Crit. Rev. Biochem. Mol. Biol. 25: 281-306.

Privalov P.L. \& Gill S.J. 1988: Stability of protein structure and hydrophobic interaction. - Adv. Protein Chem. 39: 191-234.

QuinN P.J. 1985: A lipid-phase separation model of low-temperature damage to biological membranes. - Criobiology 22: $128-146$.

QuinN P.J. 1988: Effects of temperature on cell membranes. Symp. Soc. Exp. Biol. 42: 237-258.

RAMLøv H. 2000: Aspects of natural cold tolerance in ectothermic animals. - Hum. Reprod. 15: 26-46.

RICHARDSON J.S. 1981: The anatomy and taxonomy of protein structure. - Adv. Protein Chem. 34: 167-339.

Rozsypal J. \& KošŤÁL V. 2018: Supercooling and freezing as eco-physiological alternatives rather than mutually exclusive strategies: A case study in Pyrrhocoris apterus. - J. Insect Physiol. 111: 53-62.

Rozsypal J., Goto S.G. \& Moos M. 2018a: Cold acclimation increases cold tolerance independently of diapause programing in the bean bug, Riptortus pedestris. - Bull. Entomol. Res. 108: 487-493.

Rozsypal J., Toxopeus J., Berková P., Moos M., Šimek P. \& KošŤÁL V. 2018b: Fat body disintegration after freezing stress is a consequence rather than a cause of freezing injury in larvae of Drosophila melanogaster. - J. Insect Physiol. 115: 12-19.

Russo D. 2008: The impact of kosmotropes and chaotropes on bulk and hydration shell water dynamics in a model peptide solution. - Chem. Phys. 345: 200-211.

SALT RW. 1962: Intracellular freezing in insects. - Nature 193: 1207-1208.

Salvi G., De Los Rios P. \& Vendruscolo M. 2005: Effective interactions between chaotropic agents and proteins. - Proteins 61: 492-499.

Schwarzerová K., Pokorná J., Petrásek J., Zelenková S., ČAPKOVÁ V., JANOTOVÁ I. \& OPATRNÝ Z. 2003: The structure of cortical cytoplasm in cold-treated tobacco cells: the role of the cytoskeleton and the endomembrane system. - Cell Biol. Int. 27: 263-265.

SEKI S. \& MAZUR P. 2008: Effect of warming rate on the survival of vitrified mouse oocytes and on the recrystallization of intracellular ice. - Biol. Reprod. 79: 727-737.

Seki S., Kleinhans F.W. \& Mazur P. 2009: Intracellular ice formation in yeast cells vs. cooling rate: Predictions from modeling vs. experimental observations by differential scanning calorimetry. - Cryobiology 58: 157-165.

Seki S., Edashige K., Wada S. \& Mazur P. 2011: Effect of the expression of aquaporins 1 and 3 in mouse oocytes and morulae on the nucleation temperature for intracellular ice formation. - Reproduction 142: 505-515.

Shimizu S. \& Sмiтн D.J. 2004: Preferential hydration and the exclusion of cosolvents from protein surfaces. - J. Chem. Phys. 121: $1148-1154$.

Sinclair B.J. \& Renault D. 2010: Intracellular ice formation in insects: Unresolved after 50 years? - Comp. Biochem. Physiol. (A) 155: 14-18.

Sinclair B.J., Klok C.J. \& Chown S.L. 2004: Metabolism of the sub-Antarctic caterpillar Pringleophaga marioni during cooling, freezing and thawing. - J. Exp. Biol. 207: 1287-1294.

Sinclair B.J., Coello Alvarado L.E. \& Ferguson L.V. 2015: An invitation to measure insect cold tolerance: methods, approaches, and workflow. - J. Therm. Biol. 53: 180-197. 
Smallwood M. \& Bowles D.J. 2002: Plants in a cold climate. Philos. Trans. R. Soc. (B) 357: 831-847.

Søмme L. 1999: The physiology of cold hardiness in terrestrial arthropods. - Eur. J. Entomol. 96: 1-10.

Stephens A.R., Asplen M.K., Hutchison W.D. \& Venette R.C. 2015: Cold hardiness of winter-acclimated Drosophila suzukii (Diptera: Drosophilidae) adults. - Environ. Entomol. 44: 1619-1626.

STEPONKUS P.L. \& Wiest S.C. 1978: Plasma membrane alterations following cold acclimation and freezing. In Li P.H. \& Sakai A. (eds): Plant Cold Hardiness and Freeze Stress - Mechanisms and Crop Implications. Academic Press, New York, pp. 75-91.

Štětina T., HŮla P., Moos M., ŠImeK P., Šmilauer P. \& KoŠŤÁL V. 2018: Recovery from supercooling, freezing, and cryopreservation stress in larvae of the drosophilid fly, Chymomyza costata. - Sci. Rep. 8: 4414, 13 pp.

Štětina T., Des Marteaux L.E. \& KoŠŤÁL V. 2020: Insect mitochondria as targets of freezing-induced injury. - Proc. Roy. Soc. (B) 287: 20201273, 9 pp.

Storey J.M. \& Storey K.B. 1985: Freezing and cellular metabolism in the gall fly larva, Eurosta solidaginis. - J. Comp. Physiol. (B) 155: 333-337.

Storey K.B. \& Storey J.M. 1988: Freeze tolerance in animals. Physiol. Rev. 68: 27-84.

Storey K.B. \& Storey J.M. 1991: Glucose-6-phosphate-dehydrogenase in cold hardy insects - kinetic-properties, freezing stabilization, and control of hexose-monophosphate shunt activity. - Insect Biochem. 21: 157-164.

Storey K.B. \& Storey J.M. 2010: Oxygen: Stress and adaptation in cold-hardy insects. In Denlinger D.L. \& Lee R.E. (eds): Low Temperature Biology of Insects. Cambridge University Press, New York, pp. 141-165.

Tablin F., Wolkers W.F., Walker N.J., Oliver A.E., Tsvetkova N.M., Crowe L.M. \& Crowe J.H. 2001: Membrane reorganization during chilling: Implications for long term storage. Cryobiology 43: 114-123.

TANFORD C. 1988: The hydrophobic effect and the organization of living matter. - Science 200: 1012-1018.

Tatone C., Di Emidio G., Vento M., Ciriminna R. \& Artini P.G. 2010: Cryopreservation and oxidative stress in reproductive cells. - Gynecol. Endocrinol. 26: 563-567.

Tattersall G.J., Sinclair B.J., Withers P.C., Fields P.A., SeeBacher F., Cooper C.E. \& Maloney S.K. 2012: Coping with thermal challenges: physiological adaptations to environmental temperatures. - Compr. Physiol. 2: 2151-2202.

TeETer M.M. 1991: Water-protein interactions: Theory and experiment. - Annu. Rev. Biophys. Biophys. Chem. 20: 577-600.

Teets N.M. \& Denlinger D.L. 2013: Physiological mechanisms of seasonal and rapid cold-hardening in insects. — Physiol. Entomol. 38: 105-116.

Teilum K., Olsen J.G. \& Kragelund B.B. 2011: Protein stability, flexibility and function. - Biochim. Biophys. Acta 1814: 969-976.

TimashefF S.N. 2002: Protein-solvent preferential interactions, protein hydration, and the modulation of biochemical reactions by solvent components. - Proc. Natn. Acad. Sci. USA 99: 9721-9726.
Toxopeus J. \& Sinclair B.J. 2018: Mechanisms underlying insect freeze tolerance. - Biol. Rev. Biol. Proc. Camb. Philos. Soc. 93: 1891-1914.

UlLAH J., TAKHAR P.S. \& SABLANI S.S. 2014: Effect of temperature fluctuations on ice-crystal growth in frozen potatoes during storage. - LWT-Food Sci. Technol. 59: 1186-1190.

UsSERY D.W. 2001: DNA denaturation. In Brenner S. \& Miller J.H. (eds): Encyclopedia of Genetics. Academic Press, San Diego, pp. 550-553.

VAN DER SMAN R. 2016: Phase field simulations of ice crystal growth in sugar solutions. - Int. J. Heat Mass Transf. 95: 153-161.

van Meer G., Voelker D.R. \& Feigenson G.W. 2008: Membrane lipids: where they are and how they behave. - Nat. Rev. Mol. Cell Biol. 9: 112-124.

Verbruggen N. \& Hermans C. 2008: Proline accumulation in plants: a review. - Amino Acids 35: 753-759.

Wallace E.J., Hooper N.M. \& Olmsted P.D. 2006: Effect of hydrophobic mismatch on phase behavior of lipid membranes. - Biophys. J. 90: 4104-4118.

Wang W., Nema S. \& Teagarden D. 2010: Protein aggregation Pathways and influencing factors. - Int. J. Pharm. 390: 89-99.

Watson P.F. \& MoRRIS G.J. 1987: Cold shock injury in animal cells. - Symp. Soc. Exp. Biol. 41: 311-340.

Wharton D. \& Ferns D. 1995: Survival of intracellular freezing by the Antarctic nematode Panagrolaimus davidi. - J. Exp. Biol. 198: 1381-1387.

WiLson P.W., Heneghan A.F. \& Haymet A.D.J. 2003: Ice nucleation in nature: supercooling point (SCP) measurements and the role of heterogeneous nucleation. - Cryobiology 46: 88-98.

Wolfe J. \& BRYAnt G. 2001: Cellular cryobiology: thermodynamic and mechanical effects. - Int. J. Refrig. 24: 438-450.

Wolfe J., Bryant G. \& Koster K.L. 2002: What is 'unfreezable water', how unfreezable it is and how much is there? - Cryoletters 23: 157-166.

Worland M.R., Wharton D.A. \& Byars S.G. 2004: Intracellular freezing and survival in the freeze tolerant alpine cockroach Celatoblatta quinquemaculata. - J. Insect Physiol. 50: 225232.

Yi S.-X. \& Lee R.E. 2003: Detecting freeze injury and seasonal cold-hardening of cells and tissues in the gallfly larvae, Eurosta solidaginis (Diptera: Tephritidae) using fluorescent vital dyes. —J. Insect Physiol. 49: 999-1004.

Yu S.P., Canzoniero L.M. \& Choi D.W. 2001: Ion homeostasis and apoptosis. - Curr. Opin. Cell Biol. 13: 405-411.

ZaChariassen K.E. 1985: Physiology of cold tolerance in insects. - Physiol. Rev. 65: 799-832.

ZACHARIASSEN K.E. 1992: Ice nucleating agents in cold-hardy insects. In Somero G.N., Osmond C.B. \& Bolis C.L. (eds): Water and Life. Springer, Berlin, pp. 261-281.

Zнао Z. 1997: Progress in the research on mechanism of insect cold-hardiness. — Insect Sci. 4: 265-276.

Received August 31, 2021; revised and accepted December 17, 2021 Published online January 17, 2022 